\title{
Characteristics and Evolution of Brown Carbon in Western United States Wildfires
}

Linghan Zeng ${ }^{1}$, Jack Dibb ${ }^{2}$, Eric Scheuer ${ }^{2}$, Joseph M. Katich ${ }^{3,4}$, Joshua P. Schwarz ${ }^{4}$, Ilann Bourgeois $^{3,4}$, Jeff Peischl ${ }^{3,4}$, Tom Ryerson ${ }^{3,4, a}$, Carsten Warneke ${ }^{4}$, Anne E. Perring ${ }^{5}$, Glenn S. Diskin $^{6}$, Joshua P. DiGangi ${ }^{6}$, John B. Nowak ${ }^{6}$, Richard H. Moore ${ }^{6}$, Elizabeth B. Wiggins ${ }^{6}$, Demetrios Pagonis $^{3,7, b}$, Hongyu Guo ${ }^{3,7}$, Pedro Campuzano-Jost ${ }^{3,7}$, Jose L. Jimenez ${ }^{3,7}, \mathrm{Lu} \mathrm{Xu}^{8, \mathrm{c}}$, Rodney J. Weber ${ }^{1}$

${ }^{1}$ Earth and Atmospheric Sciences, Georgia Institute of Technology, Atlanta, GA, USA

${ }^{2}$ College of Engineering and Physical Sciences, University of New Hampshire, Durham, NH, USA

${ }^{3}$ Cooperative Institute for Research in Environmental Sciences, University of Colorado Boulder, Boulder, CO, USA

${ }^{4}$ Chemical Sciences Laboratory, National Oceanic and Atmospheric Administration, Boulder, CO, USA

${ }^{5}$ Department of Chemistry, Colgate University, Hamilton, NY, USA

${ }^{6}$ NASA Langley Research Center, Hampton, VA, USA

$15 \quad{ }^{7}$ Department of Chemistry, University of Colorado Boulder, Boulder, CO, USA

${ }^{8}$ Division of Geological and Planetary Sciences, California Institute of Technology, Pasadena, CA, USA

${ }^{a}$ Now at: Scientific Aviation, Boulder, CO, USA

bNow at: Department of Chemistry and Biochemistry, Weber State University, Ogden, UT, USA

'Now at: Chemical Sciences Laboratory, National Oceanic and Atmospheric Administration, Boulder, CO, USA and Cooperative Institute for Research in Environmental Sciences, University of Colorado Boulder, Boulder, CO, USA

Correspondence to: Rodney J. Weber (rweber@eas.gatech.edu)

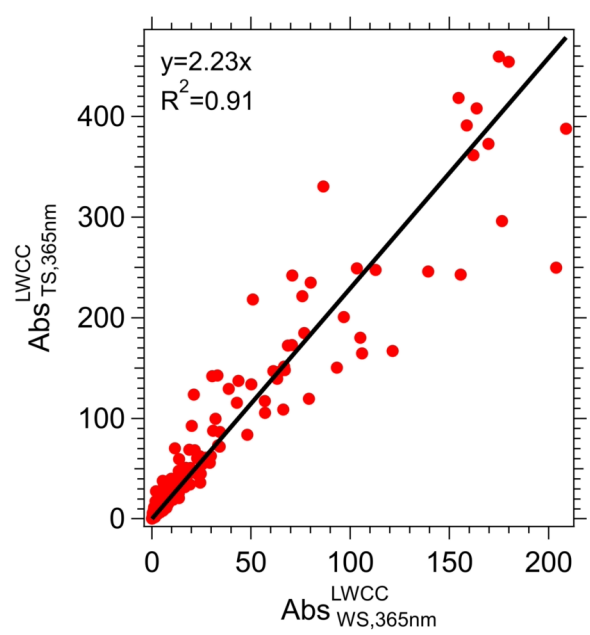


Figure S1. Comparison of TS BrC $\left(A b s_{T S, 365 n m}^{L W C C}\right)$ and $\mathrm{WS} \mathrm{BrC}\left(A b s_{W S, 365 \mathrm{~nm}}^{L W C C}\right)$ at $365 \mathrm{~nm}$ (total soluble=water soluble + methanol soluble) for all FIREX-AQ identified smoke plumes. The line represents the orthogonal distance regression of the data forced through zero.
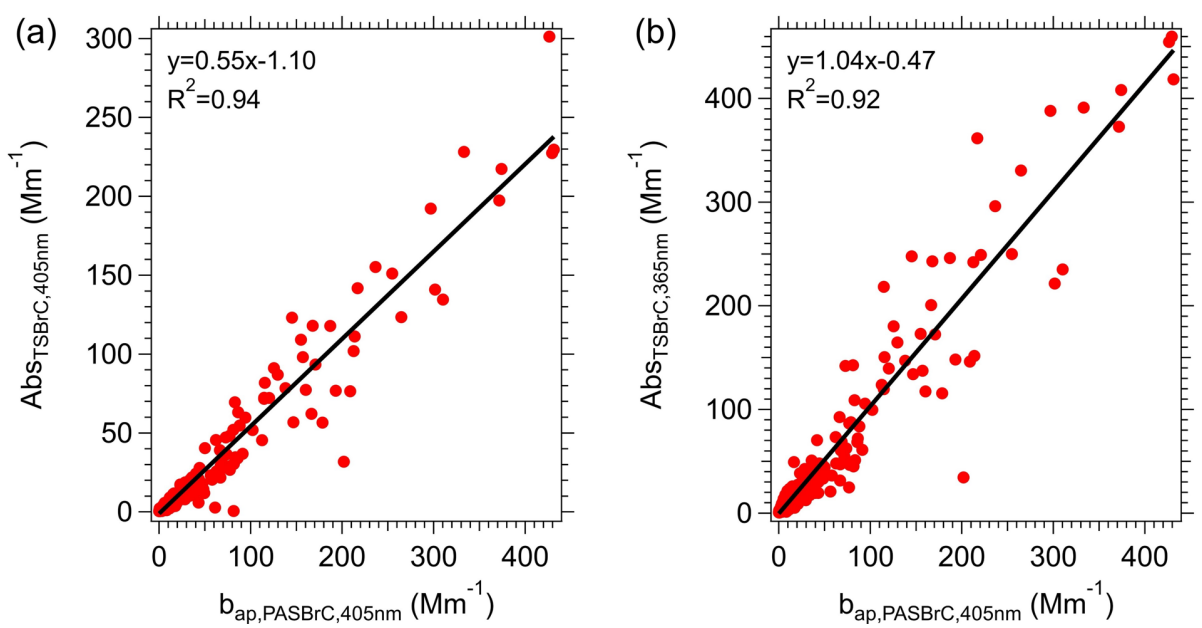

Figure S2. Comparison of $\mathrm{BrC}$ absorption in liquid (without applying the conversion factor $\mathrm{K}$ ) at (a) $405 \mathrm{~nm}$ and at (b) $365 \mathrm{~nm}$ with BrC absorption inferred from the PAS at $405 \mathrm{~nm}$. 


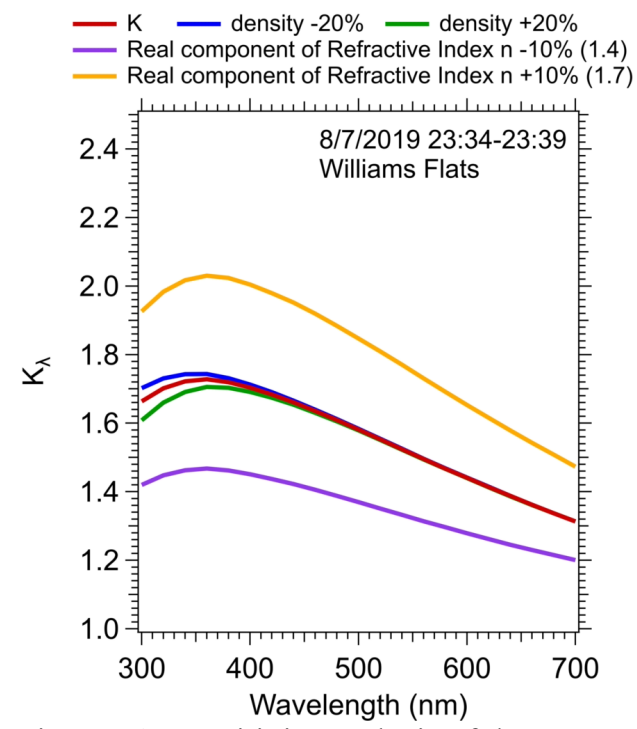

Figure S3. Sensitivity analysis of the conversion factor from absorption in liquid to aerosol based on Mie theory. The red curve, which is the same as the one in Figure 4, with assumptions that $\mathrm{n}=1.55$, and density is $1.4 \mathrm{~g} \mathrm{~cm}^{-3}$. Tuning the particle density by up (green) or down (blue) by $20 \%$ only results in less than $5 \%$ change. Altering the real component of the refractive index (n) by up (yellow) or down (purple) by $10 \%$ can lead to $\sim 20 \%$ of variation. 

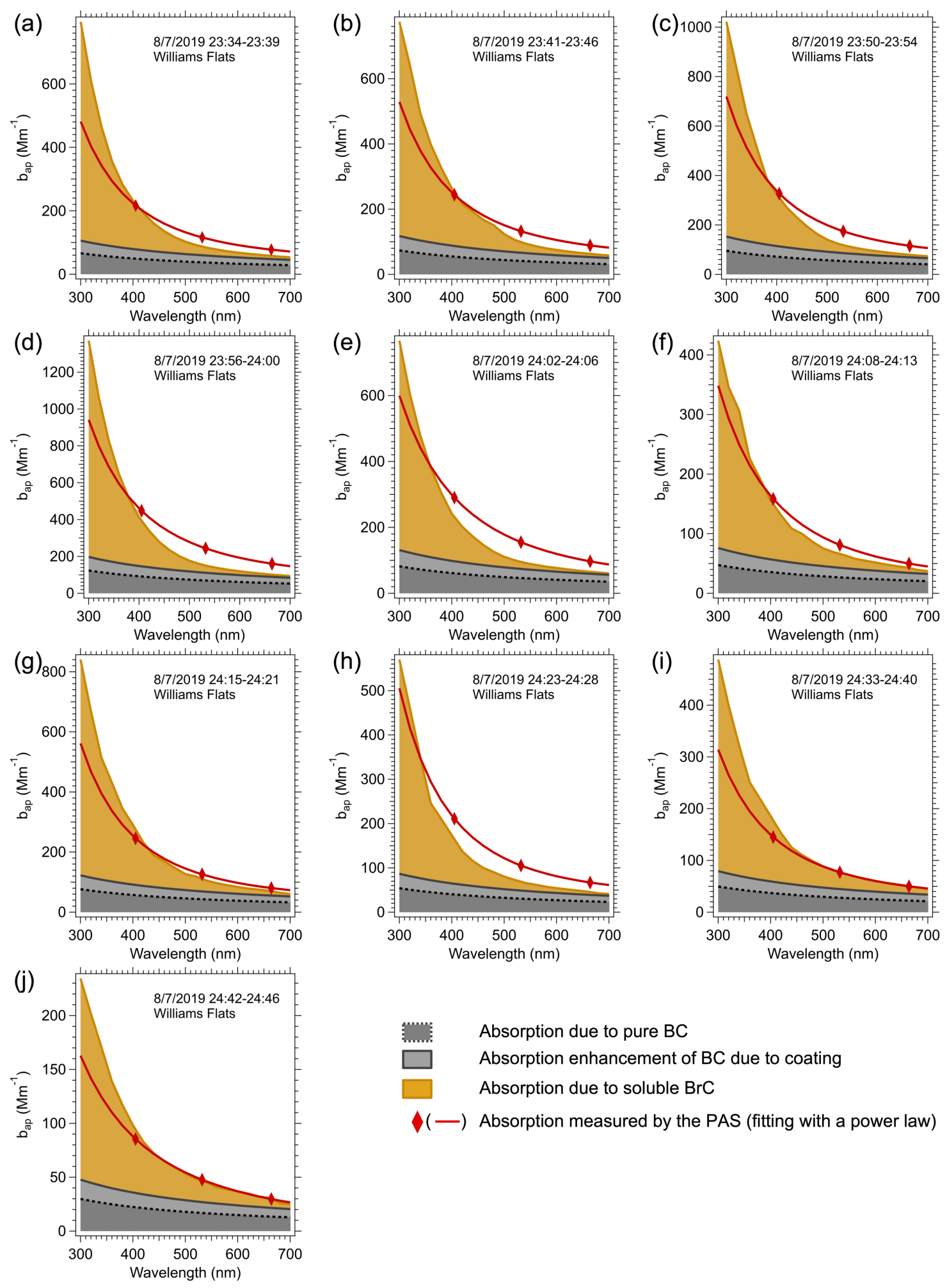

Figure S4. Closure analysis of aerosol absorption measurements for the Williams Flats fire airborne measurements starting on 7 Aug. 2019. Each plot is the average of a plume transect starting from near to further from the fire. This fire had high $\mathrm{BC}$ concentrations relative to $\mathrm{BrC}$. 

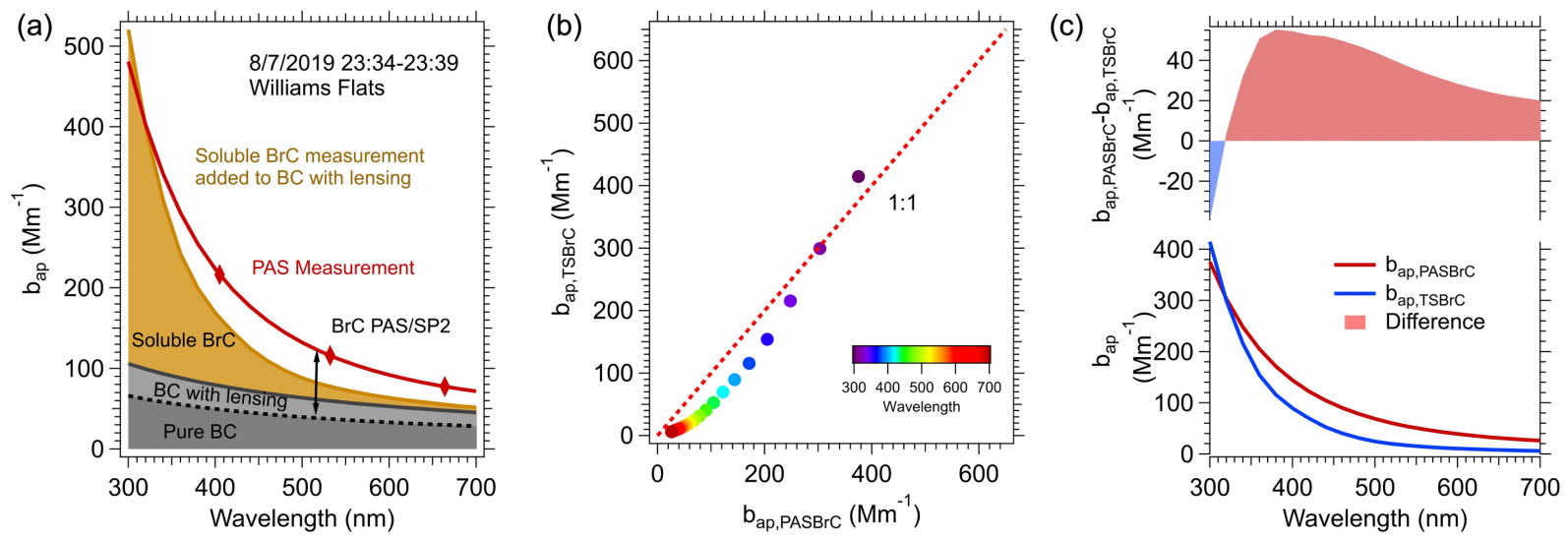

Figure S5. Similar plots shown in Figure 5, but with $\mathrm{K}=1$ (without applying the conversion from liquid to aerosol). 